\title{
O papel do médico legista e de outros profissionais forenses para a preservação do patrimônio arqueológico brasileiro
}

\section{The role of the forensic professionals in the preservation of the brazilian archeological patrymony}

\author{
Daniela Vitorio Fuzinato', Luiz Roberto Fontes², \\ Sérgio Francisco Monteiro da Silva ${ }^{3}$
}

Fuzinato DV, Fontes LR, Silva SFM. O papel do médico legista e de outros profissionais forenses para a preservação do patrimônio arqueológico brasileiro. Saúde, Ética \& Justiça. 2009;14(1):17-25

Resumo: Muitas vezes, em seu ofício, o médico legista e outros profissionais forenses são chamados para analisar restos humanos esqueletizados. Nestes achados, normalmente descobertas fortuitas, esses profissionais podem se deparar com restos ósseos que despertam interesse arqueológico, e não forense, e que, eventualmente, têm grande valor cultural e científico. Nesta situação, as leis e normas referentes à preservação e à manipulação do patrimônio arqueológico devem ser de conhecimento desses profissionais. Um exemplo recente é a descoberta, em fevereiro de 2008, de cadáveres antigos e bem conservados no Museu de Arte Sacra, localizado no Mosteiro da Luz, em pleno centro da cidade de São Paulo - evento que suscitou grande interesse acadêmico, popular e da imprensa. Este trabalho objetiva apresentar e divulgar as informações legais e normativas relativas ao patrimônio arqueológico para orientar médicos legistas e outros profissionais forenses nos procedimentos técnico-operacionais quando do achado de restos ósseos de interesse arqueológico. O patrimônio arqueológico constitui o testemunho essencial de atividades humanas do passado, favorecendo o conhecimento das origens e do desenvolvimento das sociedades humanas, sendo de fundamental importância para a humanidade inteira. Assim, a ciência da legislação de patrimônio arqueológico é fundamental para a salvaguarda do patrimônio nacional e para a melhoria e a conscientização do fazer médico-legal.

Descritores: Medicina legal. Arqueologia forense. Remanescentes ósseos humanos. Patrimônio arqueológico. Instrumentos jurídicos. Exumação.

requentemente, em seu ofício, o médico legista e outros profissionais da área forense, nomeadamente aqueles que apresentam maior contato com locais inidôneos, com a presença de remanescentes humanos esqueletizados, são solicitados para analisar tais achados.

No Brasil, particularmente no Estado de São
Paulo, pela atual estrutura das polícias, os profissionais que têm contato com remanescentes esqueletizados, além do médico legista, são aqueles cujas atividades, por ofício, incluem a ida aos locais de encontro desses. São membros da polícia judiciária e da polícia científica nos âmbitos estadual e federal. As carreiras que se enquadram

\footnotetext{
1 Médica Legista do IML - SP, Professora da Academia de Polícia Civil de São Paulo "Dr. Coriolano Nogueira Cobra" (ACADEPOL - SP).

2 Médico Legista do IML - SP, Biólogo.

3 Arqueólogo e Professor da ACADEPOL - SP.

Endereço PARA CORRESPONDÊnCIA: EPML - Centro. Av. Dr. Enéas de Carvalho Aguiar, 600, Cerqueira César, São Paulo,

SP. E-mail: daniela.dvf@polcientifica.sp.gov.br.
} 
Fuzinato DV, et al. O papel do médico legista e de outros profissionais forenses para a preservação do patrimônio.

nesse perfil são: delegado de polícia, perito criminal, investigador de polícia, agente policial, papiloscopista policial, auxiliar de papiloscopista, desenhista, fotógrafo policial e auxiliar de necropsia.

A respeito da prática da Antropologia e da Arqueologia Forenses referentes a remanescentes ósseos em locais inidôneos, são três os problemas que se apresentam: a) a diferenciação entre remanescentes humanos e não humanos; b) a distinção entre remanescentes de interesse forense $e$ não forense; c) o cálculo do número mínimo de indivíduos em deposições coletivas com mistura de ossos e dentes no local. Nesse aspecto, interessa enfatizar, neste artigo, as implicações legais relacionadas aos remanescentes humanos vinculados a causalidades penais recentes e aqueles de interesse eminentemente arqueológico.

Durante os achados de remanescentes esqueletizados, normalmente descobertas fortuitas, os profissionais podem se deparar com restos ósseos de interesse arqueológico, que não despertam interesse forense imediato, mas de grande valor cultural e científico.

Não raro, não é fácil tal distinção, sendo importante a observação in loco, por meio de técnicas e métodos específicos de escavação sistemática, e a identificação de caracteres de antiguidade dos vestígios encontrados, como cerâmicas, restos alimentares (conchas de moluscos, ossos de peixes e outros animais entre outros), intensa fragmentação dos restos ósseos (coloração normalmente mais escurecida, peso menor - exceto nos casos de determinados processos de fossilização -, maior fragilidade, ausência de tecidos orgânicos, menor resistência, menor umidade, presença de fungos na dentina), adornos, enfim, traços de antiguidade e, portanto, de procedência arqueológica (Figura 1). A presença de lesões ósseas, tratamentos odontológicos, próteses diversas, sapatos e vestes, contraceptivos femininos (DIU), bem como adornos metálicos e plásticos são indicadores da presença de remanescentes em contexto forense.

Na situação de encontro de restos ósseos de interesse arqueológico, existem normas específicas referentes à preservação e à manipulação deste patrimônio arqueológico que devem ser de conhecimento de todos os profissionais forenses.

Um exemplo recente foi o encontro, em fevereiro de 2008, de cadáveres antigos e bem conservados no Museu de Arte Sacra (MAS), localizado no Mosteiro da Luz, em pleno centro da cidade de São Paulo - evento que suscitou grande interesse acadêmico, popular e da imprensa (Figuras 2 e 3 ).

Outros casos ocorreram durante a atuação do Laboratório de Antropologia do Serviço de Identificação da Polícia Civil de São Paulo e durante atividades de prospecção em sítios arqueológicos e intervenções de empresas de construção civil.

Os médicos legistas Oscar Ribeiro de Godoy e Moncau Júnior, entre 1940 e 1957, analisaram e redigiram inúmeros laudos de perícia antropológica voltados à identificação de remanescentes esqueletizados. Esses agentes da polícia paulista depararam-se com vestígios humanos provenientes de causalidades penais diversas, como homicídio e suicídio. Trataram, também, de casos referentes ao

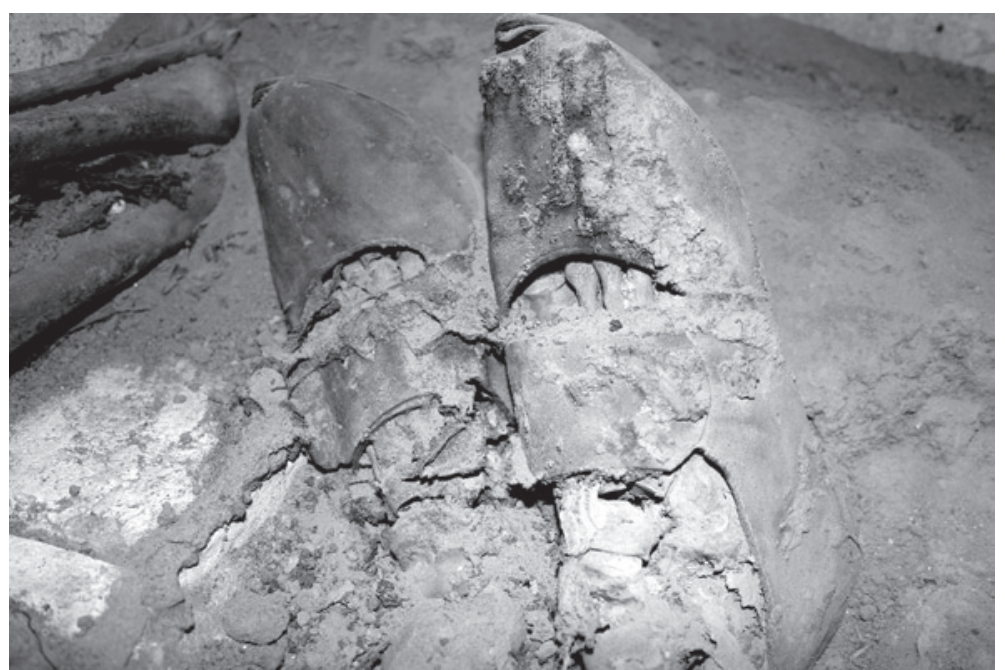

Figura 1. Vista dos sapatos de corpo mumificado - indícios de antiguidade. Mosteiro da Luz, São Paulo, 2008. 
Fuzinato DV, et al. O papel do médico legista e de outros profissionais forenses para a preservação do patrimônio.

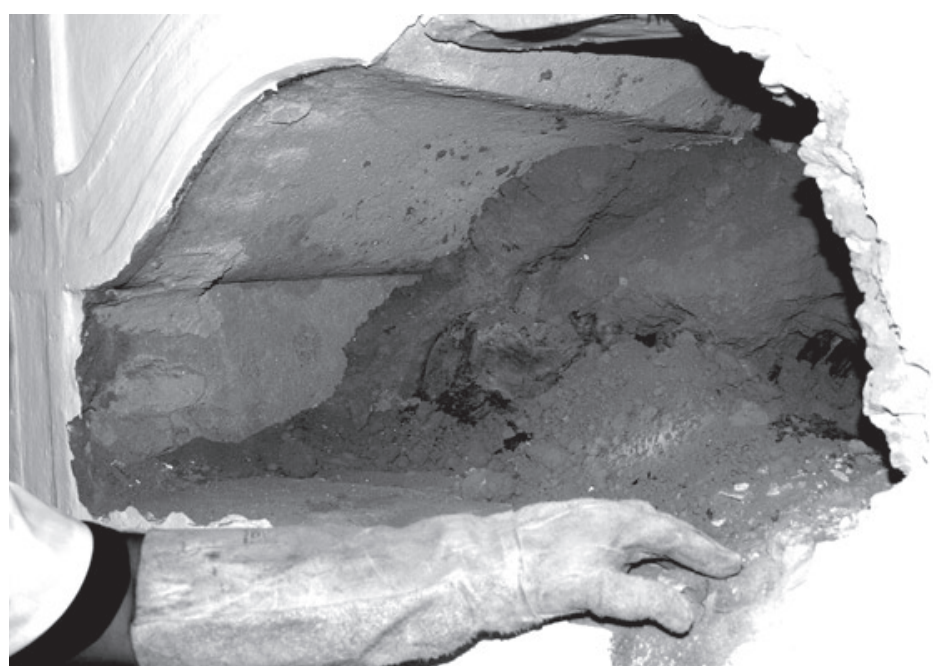

Figura 2. Descoberta fortuita de remanescentes humanos de natureza arqueológica histórica: corpo do Mosteiro da Luz, São Paulo, 2008

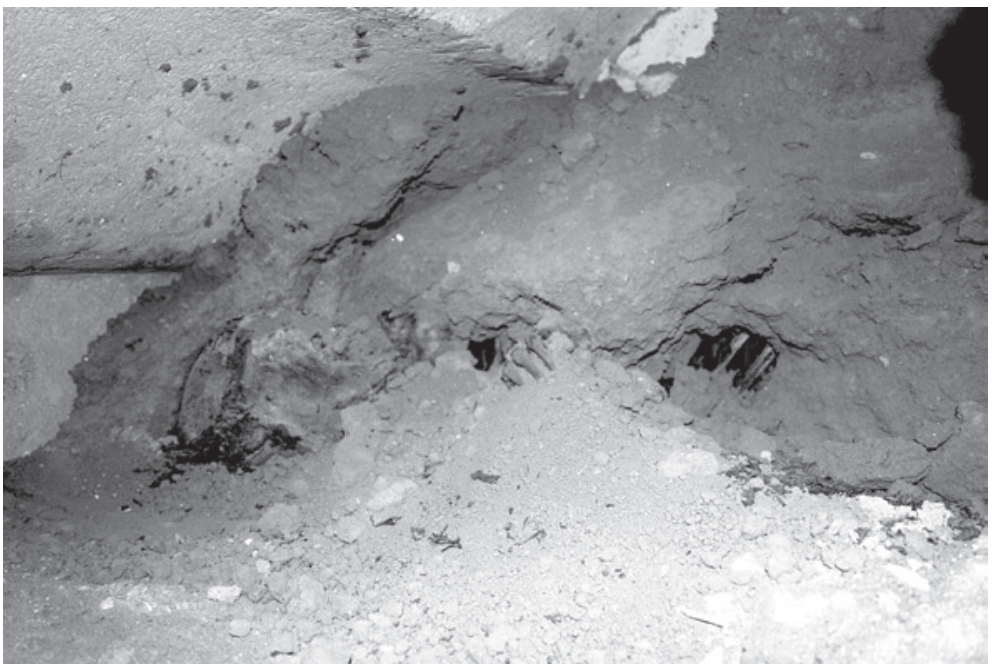

Figura 3. Detalhe das descobertas fortuitas - remanescentes humanos (bens arqueológicos) no Mosteiro da Luz, São Paulo, 2008

encontro de remanescentes não humanos, peças de estudo anatômico e remanescentes arqueológicos.

No caso do sítio pré-histórico da praia do Tenório, Ubatuba, São Paulo, assentamento com vestígios de atividades de vida e morte de caçadores-coletores-pescadores, de cerca de 1800 anos atrás, o achado da área funerária deste depósito foi feito pela ação de empresa de abertura de vias, com a participação prévia da polícia de Ubatuba, antes do início das pesquisas arqueológicas na década de 1970, que foram empreendidas pelo antigo Instituto de Pré-História da Universidade de São Paulo (USP), atual Museu de Arqueologia e Etnologia da USP.

Mais recentemente, na Ilha Anchieta, no litoral de São Paulo, durante atividades de prospecção arqueológica por arqueólogos do Museu de Ar- queologia e Etnologia e peritos do $\mathrm{MJ}$, foram localizados remanescentes humanos de um enterramento atual em área de quilombolas.

$\mathrm{Na}$ atualidade, quais seriam os procedimentos necessários para os diferentes profissionais, como os médicos, que se depararam com remanescentes arqueológicos já trazidos de campo para identificação e feitura dos atestados de óbito, os policiais, que foram chamados para responder sobre as ossadas do sítio arqueológico Tenório, e os arqueólogos, que se depararam com ossos de uma pessoa recentemente inumada no quintal da própria residência, na llha Anchieta? A lida com evidências de patrimônio arqueológico, nesses casos, está subordinada ao desenvolvimento da legislação patrimonial nas épocas em que foram 
Fuzinato DV, et al. O papel do médico legista e de outros profissionais forenses para a preservação do patrimônio.

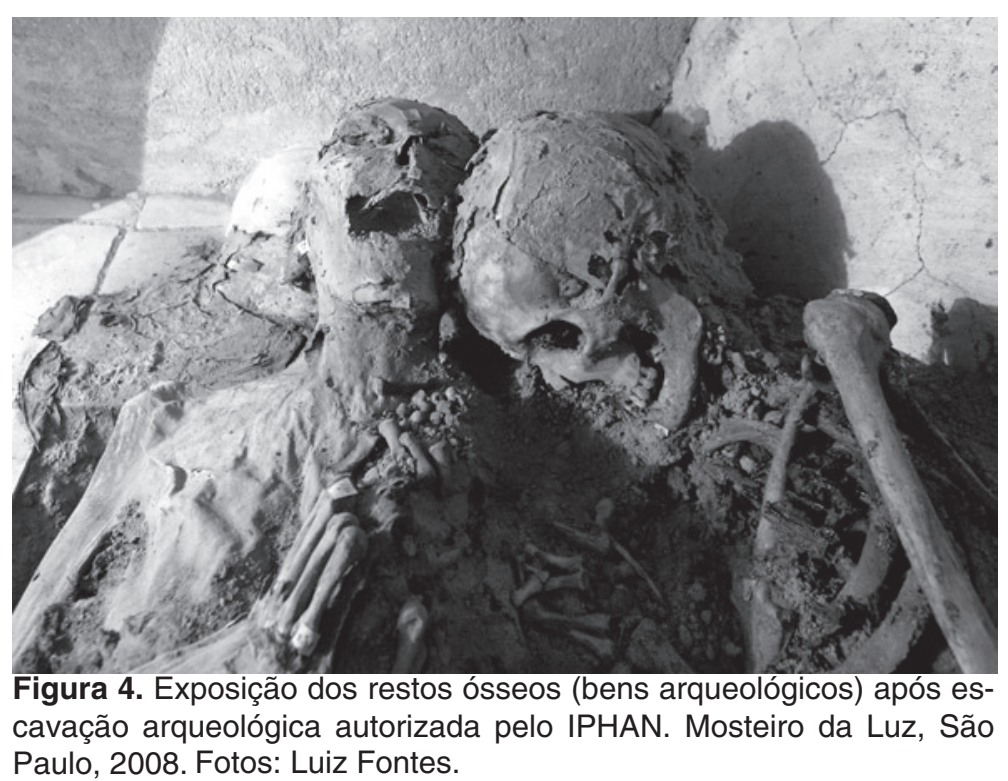

feitos os achados, entre 1940 e 2007. E atualmente, quais instrumentos legais poderiam orientar os médicos e os outros profissionais forenses na lida com remanescentes humanos de origem arqueológica?

Este trabalho tem o objetivo de apresentar e divulgar as informações legais e as normas relativas ao patrimônio arqueológico para orientar médicos legistas e outros profissionais forenses nos proce- dimentos técnico-operacionais, quando do achado de restos ósseos de interesse arqueológico.

Consequentemente, torna-se necessária a distinção in loco, preferencialmente, ou em laboratório entre casos de interesse arqueológico e de interesse forense, ambos com legislação específica.

As legislações vigentes relativas aos bens arqueológicos que devem ser de conhecimento dos

Tabela 1. Instrumentos legais de natureza constitucional e infraconstitucional relativos ao patrimônio arqueológico brasileiro

\begin{tabular}{|c|c|c|}
\hline \multirow[t]{2}{*}{ Natureza } & \multicolumn{2}{|l|}{ Instrumento } \\
\hline & Identificação & Descrição \\
\hline \multirow[t]{3}{*}{ Constitucional } & Artigo 20, linha $X$ & Sobre cavidades naturais e sítios arqueológicos \\
\hline & Artigo 23, linha III & Sobre proteção de monumentos, obras de arte e sítios arqueológicos \\
\hline & Artigo 216, linha V & $\begin{array}{l}\text { Sobre conjuntos urbanos; sítios de valor histórico paisagístico, paleonto- } \\
\text { lógico e arqueológico }\end{array}$ \\
\hline \multirow[t]{3}{*}{ Legislação } & Decreto-Lei 25 & Constituiu o SPAHN (Atual IPHAN) \\
\hline & Lei 3.924/61 & Dispõe sobre os monumentos arqueológicos e pré-históricos \\
\hline & Lei 7.542/86 & $\begin{array}{l}\text { Dispõe sobre a pesquisa e exploração de bens submersos, afundados ou } \\
\text { encalhados }\end{array}$ \\
\hline \multirow[t]{3}{*}{ Portarias } & $\begin{array}{l}06 / 79 \text { - } \\
\text { Interministerial }\end{array}$ & $\begin{array}{l}\text { Aprova normas para condução de pesquisa e exploração de bens submer- } \\
\text { sos, afundados ou encalhados }\end{array}$ \\
\hline & 07/88 - IPAHN & $\begin{array}{l}\text { Estabelece os procedimentos para licenciamento de pesquisas em sítios } \\
\text { arqueológicos }\end{array}$ \\
\hline & 230/02 - IPHAN & $\begin{array}{l}\text { Estabelece os procedimentos para licenciamento de pesquisas em proje- } \\
\text { tos de salvamento arqueológico }\end{array}$ \\
\hline Resolução & Conama 01 & $\begin{array}{l}\text { Estabelece os fundamentos dos estudos de impacto ambiental em qual- } \\
\text { quer forma de empreendimento e inclui o patrimônio cultural e arqueoló- } \\
\text { gico }\end{array}$ \\
\hline
\end{tabular}

Fonte: Azevedo Neto CX de. Práticas arqueológicas na preservação do patrimônio cultural: a intersecção com o meio ambiente e identidade cultural. In: 23 Simpósio Nacional De História, João Pessoa, 2003. João Pessoa: ANPUH; 2003. p.122. 
Fuzinato DV, et al. O papel do médico legista e de outros profissionais forenses para a preservação do patrimônio.

médicos legistas e profissionais forenses são:

A Constituição Federal em seu artigo 216, define:

"[...] constituem patrimônio cultural brasileiro os bens de natureza material e imaterial, tomados individualmente ou em conjunto, portadores de referência à identidade, à ação, à memória dos diferentes grupos formadores da sociedade brasileira, nos quais incluem: V - os conjuntos urbanos e sítios de valor histórico, paisagístico, artístico, arqueológico, palentológico, ecológico e científico [...]". "O artigo em questão sacramenta como bens da União Federal de forma indubitável os bens de natureza material e imaterial, inclusive os sítios arqueológicos" ${ }^{\prime \prime}$.

Ressaltamos, ainda, o $\S 4^{\circ}$ do mesmo artigo: "Os danos e ameaças ao patrimônio cultural serão punidos, na forma da lei." Assim, a Constituição Federal protege os bens de interesse arqueológico, definindo os limites e competências de ação tanto de profissionais forenses quanto de arqueólogos que se deparam com remanescentes humanos esqueletizados.

A Lei no 3.924 (de 26/07/1961), que dispõe sobre monumentos arqueológicos e pré-históricos, no seu art. $2^{\circ}$ estabelece:

"[...]consideram-se monumentos arqueológicos ou pré-históricos: [...] c- os sítios identificados como cemitérios, sepulturas ou locais de pouso prolongado ou de aldeamento, "estações"ou "cerâmicos", nos quais se encontram vestígios humanos de interesse arqueológico ou paleoetnográfico. Art 3o - São proibidos em todo o território nacional,o aproveitamento econômico, a destruição ou mutilação, para qualquer fim, das jazidas arqueológicas ou pré-históricas [...] bem assim dos sítios, inscrições e objetos enumerados nas alíneas b, c e d do artigo anterior. Art 5-- Qualquer ato que importe na destruição ou mutilação dos monumentos a que se refere 0 art. $2^{\circ}$ desta lei, será considerado crime contra o Patrimônio Nacional e, como tal punível de acordo com o disposto nas leis penais."

Tendo em vista tais normas vigentes, é importante que o profissional, quando do encontro de um bem arqueológico, no caso específico dos remanescentes humanos, saiba como proceder para a sua preservação.

É de suma importância que o profissional saiba que deve manter o achado arqueológico in situ, já que "qualquer translação viola o princípio segundo o qual o patrimônio deve ser conservado no seu contexto regional" (Carta de Lausanne, 1990). Além disso, o profissional deve atentar ao CAPÍTULO IV da Lei $\mathrm{n}^{\circ}$ 3.924, de 26/07/1961:

"Das descobertas fortuitas

Art 17. A posse e a salvaguarda dos bens de natureza arqueológica ou pré-histórica constituem, em princípio, direito imanente ao Estado.

Art 18. A descoberta fortuita de quaisquer elementos de interesse arqueológico ou pré-histórico, histórico, artístico ou numismático, deverá ser imediatamente comunicada à Diretoria do Instituto do Patrimônio Histórico e Artístico Nacional (IPHAN), ou aos órgãos oficiais autorizados, pelo autor do achado ou pelo proprietário do local onde tiver ocorrido. Parágrafo único. O proprietário ou ocupante do imóvel onde se tiver verificado o achado é responsável pela conservação provisória da coisa descoberta, até pronunciamento e deliberação da Diretoria do Patrimônio Histórico e Artístico Nacional.

Art 19. A infringência da obrigação imposta no artigo anterior implicará na apreensão sumária do achado, sem prejuízo da responsabilidade do inventor pelos danos que vier a causar ao Patrimônio Nacional, em decorrência da omissão."

Assim,

"as descobertas ao acaso encontram igual proteção do Estado e se acentua que a posse e a salvaguarda dos bens arqueológicos não poderá ser de pessoa, mas sim de todos, na figura do Estado. Qualquer outra forma de guarda de bens arqueológicos deve ser obrigatoriamente designada através de portaria específica editada pelo IPHAN para esse fim"'.

Foi o que ocorreu com o achado fortuito de corpos de interesse arqueológico no Museu de Arte Sacra (MAS). A equipe de trabalho que fortuitamente descobriu os bens arqueológicos, e que é responsável pelo presente artigo, comunicou o IPHAN a respeito do achado por meio do próprio MAS. Como houve, por parte da equipe, um interesse em participar das atividades científicas relacionadas a essas escavações arqueológicas, procedeu-se, através do IPHAN, à abertura de um processo para avaliação, tendo ao final uma portaria, número 12 de 09 de abril de 2008, de autorização para um projeto de pesquisa arqueológica denominado originalmente "Arqueologia Funerária do Mosteiro da Luz: Túmulos da Fundação das Concepcionistas em São Paulo" e atualmente denominado "Arqueologia Funerária no Mosteiro da Luz".

É relevante a portaria do IPHAN 007 de 01/12/88 que "estabelece os procedimentos necessários à 
Fuzinato DV, et al. O papel do médico legista e de outros profissionais forenses para a preservação do patrimônio.

comunicação prévia, às permissões e às autorizações para pesquisa e escavações arqueológicas em sítios arqueológicos e pré-históricos previstas na Lei no 3.924, de 26/07/1961." e, portanto, normatiza os planos de trabalhos científicos.

Com relação às penalidades para os crimes contra o Patrimônio Nacional, ressaltamos o art. 165 do Código Penal Brasileiro (CPB): "destruir, inutilizar ou deteriorar coisas tombadas pela autoridade competente em virtude de valor artístico, arqueológico ou histórico" e o art. 166 do CPB: "alterar, sem licença da autoridade competente, o aspecto de local especialmente protegido por lei.". Também citamos as seguintes normatizações, aplicáveis para penalidades sobre bens arqueológicos: Lei n. 7347 de 24/07/85, Lei 9605 de 12/02/98, Decreto n. 3179 de 21/09/99.

Além dessas legislações e normas nacionais, existem as recomendações internacionais aplicáveis em matéria de pesquisas arqueológicas que devem ser conhecidas (Tabela 2).

O encontro de remanescentes humanos, comumente esqueletizados, implica na observância de instrumentos legais pertinentes para cada caso: remanescentes de interesses arqueológico, antropológico, forense ou sem interesse imediato. Esse encontro pode ter sido norteado pelas exumações legais ou ilegais ${ }^{10}$ (Tabela 3).

Nos casos específicos de exumações judiciárias, incluem-se resoluções da Polícia Judiciária e do Código de Processo Penal (Tabela 4).

A convergência entre os procedimentos científicos da arqueologia e os de perícia forense nos casos de encontros de remanescentes humanos esqueletizados indica a necessidade de desenvolvimento da arqueologia e da antropologia em meio forense no Brasil a partir do estudo sobre o estado da arte dessas disciplinas. Os instrumentos legais relativos aos remanescentes humanos encontrados em locais de crimes e aos referentes aos remanescentes arqueológicos indicam a necessidade da verificação da área de interesse dos materiais humanos recuperados: forense, arqueológico, antropológico ou sem interesse. Instrumentos legais constitucionais e infraconstitucionais relacionados ao patrimônio arqueológico incluem os cemitérios e remanescentes humanos. Instrumentos do direito

Tabela 2. Instrumentos para a preservação patrimonial de âmbito internacional

\begin{tabular}{|c|c|}
\hline Documento & Data da criação \\
\hline Carta de Atenas - Sociedade das Nações & outubro de 1931 \\
\hline Recomendação de Nova Delhi - Arqueologia & dezembro de 1956 \\
\hline Recomendação de Paris - Paisagens e Sítios & dezembro de 1962 \\
\hline Carta de Veneza - Monumentos e Sítios & maio de 1964 \\
\hline Recomendação de Paris - Obras Públicas ou Privadas & novembro de 1968 \\
\hline $\begin{array}{l}\text { Conferência de Nara - Conferência de autenticidade em relação a convenção do Patrimônio } \\
\text { Mundial }\end{array}$ & - \\
\hline Convenção de Paris - Patrimônio Mundial & novembro de 1972 \\
\hline Declaração de Estocolmo - Ambiente Humano & junho de 1972 \\
\hline Carta de Turismo Cultural - ICOMOS & 1976 \\
\hline Carta de Washington - ICOMOS- Cidades históricas & 1986 \\
\hline Carta de Petrópolis - Centros históricos & 1987 \\
\hline Carta de Cabo Frio - Encontro de Civilizações nas Américas & outubro de 1989 \\
\hline Carta de Lausanne - Carta para a proteção e gestão do patrimônio arqueológico & 1990 \\
\hline Carta de Fortaleza & 1997 \\
\hline $\begin{array}{l}\text { Decisão } 460 \text { - Sobre proteção e recuperação de bens culturais do patrimônio arqueológico, } \\
\text { histórico, etnológico, paleontológico e artístico da Comunidade Andina }\end{array}$ & 25 de maio de 1999 \\
\hline
\end{tabular}

Fonte: adaptado de Azevedo Netto, 2008a. p. 10;2008b, p.4 e Iphan 
Fuzinato DV, et al. O papel do médico legista e de outros profissionais forenses para a preservação do patrimônio.

Tabela 3. Classificação das exumações

\begin{tabular}{l|l|l}
\hline Tipo de Exumação & \multicolumn{2}{|l}{ Classificações } \\
\hline $\begin{array}{l}\text { Legais ou legítimas: efetuadas de acordo } \\
\text { com o direito, permitidas pelo direito }\end{array}$ & Voluntárias & $\begin{array}{l}\text { Remoção } \\
\text { Traslação } \\
\text { Científica }\end{array}$ \\
\cline { 2 - 3 } & Administrativas & $\begin{array}{l}\text { Administrativas } \\
\text { Judiciais }\end{array}$ \\
\cline { 2 - 3 } $\begin{array}{l}\text { Ilegais ou criminais: contrárias ao direito; } \\
\text { objeto do Direito Funerário Penal }\end{array}$ & $\begin{array}{l}\text { Impedimento ou Perturbação de Cerimônia Funerária } \\
\text { Violação de sepultura } \\
\text { Destruição, Subtração ou Ocultação de Cadáver Violação de sepultura } \\
\text { Vilipêndio a Cadáver } \\
\text { Ofensa à Honra dos Mortos } \\
\text { Contravenções Penais }\end{array}$ \\
\hline
\end{tabular}

Fonte: adaptado de Silva, 2000. p. 504.

Tabela 4. Características similares e distintivas entre as exumações legais judiciária e voluntária científica:

\begin{tabular}{|c|c|}
\hline $\begin{array}{l}\text { Exumação legal judiciária / administrativa: desenter- } \\
\text { ramento }\end{array}$ & $\begin{array}{l}\text { Exumação legal voluntária científica ou judiciária: } \\
\text { escavação arqueológica forense }\end{array}$ \\
\hline $\begin{array}{l}\text { 1. Histórico do caso - motivos que levaram à exumação, } \\
\text { denúncia, registros de ocorrências, inquéritos, exibi- } \\
\text { ção do livro de Registro de Inumações, com nome do } \\
\text { morto, data do sepultamento, número do atestado de } \\
\text { óbito, número da quadra, do jazigo e da gaveta. }\end{array}$ & $\begin{array}{l}\text { 1. Projeto de escavação com histórico do sítio: motivos } \\
\text { que levaram à pesquisa, hipóteses e emprego de es- } \\
\text { cavação arqueológica, mapeamento, análise de aero- } \\
\text { fotos, características ambientais, geomorfológicas, } \\
\text { climáticas, de intervenções antrópicas. }\end{array}$ \\
\hline $\begin{array}{l}\text { 2. Legistas presentes para coleta de amostras para aná- } \\
\text { lises laboratoriais }\end{array}$ & $\begin{array}{l}\text { 2. Equipe inter ou multidisciplinar para escavação siste- } \\
\text { mática e coleta de amostras para análises laborato- } \\
\text { riais }\end{array}$ \\
\hline $\begin{array}{l}\text { 3. Presença de: autoridade policial, legistas, fotógrafo, } \\
\text { coveiro, auxiliares, pessoa da família ou relacionada } \\
\text { ao morto para auxiliar na identificação }\end{array}$ & $\begin{array}{l}\text { 3. Coordenação de autoridade policial, peritos, médicos } \\
\text { legistas, arqueólogos, familiares, com eventual partici- } \\
\text { pação de ONG's e peritos do MP ou MJ }\end{array}$ \\
\hline $\begin{array}{l}\text { 4. Exumação legal judicial: procedimentos diurnos, pre- } \\
\text { ferencialmente matutinos, com instrumental apropria- } \\
\text { do; eventual autorização para extensão de prazos para } \\
\text { a perícia de local }\end{array}$ & $\begin{array}{l}\text { 4. Exumação legal voluntária científica ou legal judicial: } \\
\text { escavação arqueológica forense - procedimentos } \\
\text { diurnos ou noturnos, com instrumental arqueológico } \\
\text { necessário e eventual autorização para extensão de } \\
\text { prazos das atividades de campo }\end{array}$ \\
\hline $\begin{array}{l}\text { 5. Legislação própria: CPP - Art. 163-166; Resolução } \\
\text { SSP-194/99, legislação parcial (Decreto } 42.847 \text { de } \\
\text { 9/02/98 sobre a estrutura da SPTC), Resolução SSP- } \\
\text { SP } 382 \text { de } 1 / 9 / 99 \text {, seção IV -VII, Port DGP } 6,15 / 02 / 96 \\
\text { (entorpecentes e seu transporte) }\end{array}$ & $\begin{array}{l}\text { 5. Legislação ref bens arqueológicos - Lei 3.924/61; Art. } \\
\text { 165/ legislação parcial (Decreto } 42.847 \text { de 9/02/98 so- } \\
\text { bre a estrutura da SPTC, Resolução SSP-SP } 382 \text { de } \\
\text { 1/9/99, seção IV -VII), instrumentos legais do IPHAN }\end{array}$ \\
\hline $\begin{array}{l}\text { 6. Registro fotográfico do corpo na posição em que foi } \\
\text { encontrado (fotógrafo técnico pericial) }\end{array}$ & $\begin{array}{l}\text { 6. Registro fotográfico dos vestígios em vários níveis de } \\
\text { evidenciação (fotógrafo técnico pericial) }\end{array}$ \\
\hline $\begin{array}{l}\text { 7. Levantamento topográfico (desenhista técnico peri- } \\
\text { cial) }\end{array}$ & $\begin{array}{l}\text { 7. Levantamento topográfico (desenhista técnico peri- } \\
\text { cial) }\end{array}$ \\
\hline $\begin{array}{l}\text { 8. Elaboração de laudo pericial/ laudo necroscópico: pa- } \\
\text { receres médicos periciais }\end{array}$ & $\begin{array}{l}\text { 8. Elaboração de laudo pericial/ laudo necroscópico, re- } \\
\text { dimensionamento da investigação, eleboração de re- } \\
\text { latório do arqueólogo e complementações necessárias } \\
\text { ao laudo técnico pericial }\end{array}$ \\
\hline
\end{tabular}


Fuzinato DV, et al. O papel do médico legista e de outros profissionais forenses para a preservação do patrimônio.

funerário penal incluem a exumação legal e suas variações que interessam à Polícia Judiciária.

O médico legista e os outros profissionais forenses, relacionando-se com remanescentes esqueletizados provenientes de escavações em locais de crime e exumações tradicionais, possuem diante de si prerrogativas de instrumentos legais de diferentes instâncias, que incluem os constitucionais, infraconstitucionais, os previstos no Código Penal Brasileiro, no Código de Processo Penal, nas resoluções e portarias específicas da Polícia. Nesse contexto, a medicina apresenta novas perspectivas para construir o conhecimento sobre a sua história - bioarqueologia, antropologia forense, arqueologia forense e sobre os amparos legais disponíveis quando da lida com cadáveres humanos e seus remanescentes ósseos para além da área médica. A atuação dos profissionais forenses pressupõe o conhecimento preliminar da ampla gama de instrumentos legais, tratados resumidamente neste artigo.

\section{Conclusões}

O patrimônio arqueológico constitui o "testemunho essencial sobre as atividades humanas do passado" (Carta de Lausanne, 1990), favorecendo o conhecimento das origens e do desenvolvimento das sociedades humanas, sendo de fundamental importância para a humanidade inteira. A ciência da legislação de patrimônio arqueológico por médicos legistas e outros profissionais forenses é fundamental para a salvaguarda do patrimônio nacional e para a melhoria e a conscientização do fazer médico-legal, e estes profissionais poderão contribuir com o desenvolvimento das sociedade humanas e, portanto, "de toda a humanidade, permitindo-Ihe identificar suas raízes culturais e sociais" (Carta de Lausanne, 1990), contribuindo para a criação de uma consciência preservacionista, preocupada com a memória e a identidade coletivas².

Fuzinato DV, Fontes LR, Silva SFM. The role of the forensic professionals in the preservation of the brazilian archeological patrymony. Saúde, Ética \& Justiça. 2009;14(1):17-25

AвstRAct: Often in the course of their work the forensics are called to study human skeletal remains. These usually fortuitous findings may face the forensics with skeletal remains of archaeological, cultural and scientific importance, with no forensic interest. In such a situation the forensics should be aware of laws and standards regarding to the preservation and handling of the archaeological heritage. An example at hand is the February 2008 finding of well-preserved ancient bodies within the Museum of Sacred Art, located in the Mosteiro da Luz, in the heart of São Paulo City -an event that aroused great academic, popular and media interest. This paper aims at presenting and disseminating laws and regulations concerning the archaeological heritage in order to guide forensics in technical and operational procedures on the occasion of the discovery of human skeletal remains of archaeological interest. The archaeological heritage is the key witness on past human activities, promoting the knowledge of the origins and development of human societies and it is of fundamental importance to mankind. Thus, knowledge about archaeological heritage laws is essential to safeguard the national heritage, and for the improvement and awareness of medico-legal know-how.

KEYwords: Forensic medicine. Forensic archaeology. Human skeletal remains. Archaeological heritage. Applicable legislation. Exhumation.

REFERÊNCIAS

1. Azevedo Netto CX. Preservação do patrimônio arqueológico - reflexões através do registro e transferência da informação. Ci Inf, Brasília. 2008;37(3):7-17.

2. Azevedo Netto CX. Informação e patrimônio arqueológico: formação de memórias e construção de identidades. In: IX ENANCIB - Diversidade Cultural e Políticas de Informação, 2008. Comunicação oral GT-02 - Organização e Representação do Conhecimento

3. Bastos RL, Souza MC, Gallo H, organizadores. Normas e gerenciamento do patrimônio arqueológico. São Paulo: 9 SR/ IPHAN; 2005

4. Bass WM, Birkby WH. Exhumation: the method could make the difference. FBI - Law Enforcement Bull Forensic Sci. 1978, July: 6-1.

5. Croce D, Junior DC. Manual de medicina legal. 3a ed São Paulo: Editora Saraiva; 1996. 
Fuzinato DV, et al. O papel do médico legista e de outros profissionais forenses para a preservação do patrimônio.

6. Dupras TL, Schultz JJ, Wheeler SM, Willians LJ. Forensic recovery of human remains: archaeological approaches. [S.I.]: CRC Press; 2005.

7. Hoshower LM. Forensic archaeology and the need for flexible excavation strategies: a case study. Forensic Sci. 1998;43(1):53-6.

8. Hunter JR, Cox M. Forensic archaeology - advances in theory and practice. London: Routledge Taylor \& Francis Group; 2006.

9. Mori VH, Souza MC, Bastos RL, Gallo H. organizadores. Patrimônio: atualizando o debate. São Paulo: 9a SR/IPHAN; 2006.

Artigo recebido em: 12/02/2009.

Aprovado em: 02/04/2009.
10. Silva JAF. Tratado de direito funerário. São Paulo: Método; 2000. t.1,2.

11. Silva SFSM, Oliveira RN. Forensic archaeology in the Academy of Civil Police, Sao Paulo State, Brazil. In: 1st Paleopathology Association Meeting In South América. Progam and abstracts. Rio de Janeiro: Escola Nacional de Saúde Pública Sergio Arouca; 2005. p. 55.

12. Ubelaker DH, Blaus S. Handbook of forensic archaeology and anthropology (World Archaeological Congress Research Handbooks). [S.I.]: Left Coast Press; 2006 